Document, create and translate knowledge: the mission of ReFORM, the Francophone IOC Research Centre for Prevention of Injury and Protection of Athlete Health

\author{
Géraldine Martens (D) , ${ }^{1}$ Pascal Edouard (D) , 2,3,4 Philippe Tscholl (D) , \\ François Bieuzen (D) , ${ }^{6}$ Laurent Winkler (D) , ${ }^{2}$ Jan Cabri (D) , \\ Axel Urhausen (D) , 7,8,9 Gaël Guilhem (1D) ,' 2,10 Jean-Louis Croisier (D) , 11 \\ Patricia Thoreux (D) , ${ }^{2,12,13}$ Suzanne Leclerc (D) , ${ }^{6}$ Didier Hannouche (i) , \\ Jean-François Kaux (D) , ${ }^{11}$ Sébastien Le Garrec, ${ }^{2}$ Romain Seil (D) 7,8,14
}

The International Olympic Committee (IOC) has supported athletes' health

${ }^{1}$ ReFORM IOC Research Centre for Prevention of Injury and Protection of Athlete Health, University Hospital of Liege, Liege, Belgium

${ }^{2}$ ReFORM IOC Research Centre for Prevention of Injury and Protection of Athlete Health, Institut National du Sport de l'Expertise et de la Performance, Paris, France ${ }^{3}$ Department of Clinical and Exercise Physiology, Sports Mecicine Unit, University Hospital of Saint-Etienne,

Saint-Etienne, France

${ }^{4}$ Inter-university Laboratory of Human Movement Science (LIBM EA 7424), University of Lyon, University Jean Monnet, Saint-Etienne, France

${ }^{5}$ ReFORM IOC Research Centre for Prevention of Injury and Protection of Athlete Health, University Hospitals Geneva Department of Orthopaedic Surgery and

Traumatology of the Musculoskeletal System, Geneve, Switzerland

${ }^{6}$ ReFORM IOC Research Centre for Prevention of Injury and Protection of Athlete Health, Institut National du

Sport du Quebec, Montreal, Quebec, Canada

${ }^{7}$ ReFORM IOC Research Centre for Prevention of Injury and Protection of Athlete Health, Luxembourg Institute of Research in Orthopedics, Sports Medicine and Science, Luxembourg, Luxembourg

${ }^{8}$ Clinique du Sport, Centre Hospitalier de Luxembourg, Luxembourg, Luxembourg

${ }^{9}$ Human Motion, Orthopedics, Sports Medicine and Digital Methods, Luxembourg Institute of Health,

Luxembourg, Luxembourg

${ }^{10}$ Laboratory Sport, Expertise and Performance (EA

7370), Institut National du Sport, de l'Expertise et de la Performance, Paris, France

${ }^{11}$ ReFORM IOC Research Centre for Prevention of Injury and Protection of Athlete Health, Physical Medicine and Sports Traumatology Department, FIFA Medical Centre of Excellence, FIMS Collaborative Centre of Sports Medicine, University and University Hospital of Liege, Liege, Belgium

${ }^{12}$ Centre $d^{\prime}$ Investigations en Médecine du Sport (CIMS), Hôpital Hôtel-Dieu APHP, Paris, France

${ }^{13}$ Arts et Métiers Institute of Technology, Institut de

Biomécanique Humaine Georges Charpak, Université

Sorbonne Paris Nord, Paris, France

${ }^{14}$ Department of Orthopaedic Surgery, Centre

Hopsitalier de Luxembourg, Clinique d'Eich,

Luxembourg, Luxembourg

Correspondence to Dr Géraldine Martens, Physical Medicine and Sport Traumatology Department, SportS2, Central University Hospital of Liege, Liege 4000,

Belgium; geraldine.martens@uliege.be protection $^{1}$ by funding research centres dedicated to prevention and treatment of sports-related injuries and illnesses. ${ }^{2}$ After establishing four centres in $2009,{ }^{2}$ the IOC research centres network expanded to 9 institutions in $2014^{3}$ and the 2019 round recognised 11 centres. ${ }^{4}$ Here we introduce ReFORM-an international Frenchspeaking network of five institutions. ${ }^{5}$

\section{WHO IS REFORM?}

ReFORM stands for Réseau Francophone Olympique de la Recherche en Médecine $d u$ Sport, and we embrace the IOC's vision to foster international collaborations. ${ }^{5}$ Five intercontinental countries created this French-speaking Olympic network for Research in Sports Medicine, with support from their national Olympic Committees (table 1):

- French National Institute of Sport (INSEP), Paris, France.

- Physical Medicine and Sport Traumatology Department (SportS²), University and University Hospital of Liège, Belgium.

- Luxembourg Institute of Research in Orthopaedics, Sports Medicine and Science (LIROMS), Luxembourg.

- Institut National du Sport du Québec (INS), Montréal, Québec, Canada.

- Department of Orthopaedic Surgery and Traumatology, Geneva University Hospitals (HUG), Switzerland.

Together, they serve hundreds of elite athletes and are at the forefront of highlevel sports medicine and research in their respective countries.

\section{WHAT MAKES REFORM UNIQUE?}

ReFORM is the only IOC Research Centre where French is the first common language. As an official Olympic language (with English), French has a limited representation in the scientific output of the IOC, despite being spoken by more than 300 million people in 50 countries worldwide, including sports stakeholders (ie, coaches, physicians and athletes). We will help bring quality French-language evidence and practice experience to the anglophone world and help mobilise anglophone sports medicine and sports physiotherapy to francophone countries. ${ }^{6}$ As an active participant of the Francophonie (French-speaking world) in Sports Medicine and the IOC, ReFORM will bring quality francophone evidence and practice to the anglophone world.

Another strength of this consortium lies in its collaborative effort, gathering strong complementary expertise in the various subspecialisations of sports medicine, in line with the IOC Medical Commission objectives. These fields include exercise medicine and physiology, sports cardiology, orthopaedic surgery, as well as prevention and rehabilitation of sports injuries. Scientific experience is also well represented with extended expertise in biomechanics, epidemiology, imaging, clinical biology, psychology and sociology.

We appreciate that conducting efficient research across five major institutions disseminated around the globe comes with its own peculiar challenges. Each centre has different healthcare and sports performance systems, as well as political and academic environments, in addition to being geographically distant. To catalyse synergies between the centres, a scientific coordinator (GM) is responsible for setting and following up ReFORM's research projects. This challenging position enables the five centres to streamline collaborative work.

\section{WHAT ARE THE FOCUS AREAS FOR} REFORM?

ReFORM currently follows three main approaches:

- Documenting sports injury prevention on-field practices through surveying French-speaking sports communities' stakeholders about theoretical knowledge on sports injuries, their management, history and outcome, as well as existing education tools. The current focus lies on concussions and shoulder injuries. Mapping injury prevention practice and knowledge across several countries and cultures will open the path to tailored training and prevention programmes, adapted to the specificities of each community.

- Create knowledge on injury prevention and athlete protection through ReFORM's resources, allowing tackling each aspect of the well-known 
Table 1 ReFORM members and respective expertise

\begin{tabular}{|c|c|c|}
\hline Country & Institution & Main expertise \\
\hline Belgium & $\begin{array}{l}\text { Physical Medicine and Sport Traumatology Department (SportS2), University and } \\
\text { University Hospital of Liège }\end{array}$ & $\begin{array}{l}\text { Biomechanics, exercise physiology, clinical biology, multidisciplinary } \\
\text { (sub)elite athlete medical follow-up }\end{array}$ \\
\hline Canada & Institut National du Sport du Québec (INS), Montréal & $\begin{array}{l}\text { Data science, multidisciplinary elite athlete medical follow-up, load } \\
\text { monitoring, neuroscience }\end{array}$ \\
\hline France & French National Institute of Sport (INSEP), Paris & $\begin{array}{l}\text { Multidisciplinary elite athlete medical follow-up, epidemiology, } \\
\text { imaging, biomechanics }\end{array}$ \\
\hline Luxembourg & $\begin{array}{l}\text { Luxembourg Institute of Research in Orthopaedics, Sports Medicine and Science } \\
\text { (LIROMS) }\end{array}$ & Orthopaedics, biomechanics, exercise physiology, sports cardiology \\
\hline Switzerland & $\begin{array}{l}\text { Department of Orthopaedic Surgery and Traumatology, Geneva University } \\
\text { Hospitals (HUG) }\end{array}$ & Epidemiology, orthopaedics, biomechanics, musculoskeletal biology \\
\hline
\end{tabular}

sports injury prevention sequence ${ }^{7}$; the following themes will be addressed:

- Epidemiology: taking part in international initiatives to feed large injury registries and considering setting up new ones.

- Aetiology: better understanding factors and mechanisms of injury occurrence, with a multifactorial approach (eg, biomechanics, physiology and psychology) and different analytical methods (eg, machine learning) with specific injury models (eg, anterior cruciate ligament, shoulder and lower limb muscle injuries).

- Prevention: implementing community-tailored education programmes within the scope of the concussion project and beyond. Thanks to the proximity and strong collaborative interfaces developed with athletes and staffs, individualised prevention strategies will also be developed and continuously evaluated.

- Disseminating knowledge on prevention and protection by providing the Frenchspeaking sports community with high levels of theoretical and practical knowledge on sports medicine and athletes' health and while learning from the community practices. This bidirectional flow between the clinical research teams and the sports communities represents a unique opportunity for integrated knowledge translation. ReFORM has also started translating the IOC Consensus Statements into French as a milestone to make information accessible for both scientific and sports communities.

\section{REFORM'S VISION}

ReFORM offers a multidisciplinary, multicultural and multicentre approach and collaborates on innovative international research to support the success of its various partners in the quest for Olympism. To enhance the health and prevent injuries of all athletes, ReFORM strives to increase knowledge and expertise, through a close relationship with sport stakeholders, within the Francophonie and beyond.

Twitter Géraldine Martens @MartensGege, Pascal Edouard @PascalEdouard42, François Bieuzen @FrancoisBieuzen, Jan Cabri @jancabri, Jean-François Kaux@JFKaux, Sébastien Le Garrec @doclegarrec and Romain Seil @RomainSeil

Contributors GM and PE wrote the manuscript. RS drafted the manuscript outline. PTs, FB, LW, JC, AU, GG, J-LC, PTh, SL, DH, J-FK and SLG critically reviewed the manuscript for intellectual content.

Funding The French-speaking network Réseau Francophone Olympique de la Recherche en Médecine du Sport (ReFORM) is recognised as a research centre for the Prevention of Injury and IIIness and the Protection of Athletes by the Olympic Committee (IOC). As a member of the IOC Medical Research Network, ReFORM has received funding from the IOC to establish long-term research programmes on the prevention of injuries and illnesses in sport for the protection of athlete health. The first author (GM) is paid full-time by ReFORM through the IOC funding.

\section{Competing interests None declared.}

Patient consent for publication Not required.

Provenance and peer review Not commissioned; externally peer reviewed.

\section{(2) \\ OPEN ACCESS}

Open access This is an open access article distributed in accordance with the Creative Commons Attribution Non Commercial (CC BY-NC 4.0) license, which permits others to distribute, remix, adapt, build upon this work non-commercially, and license their derivative works on different terms, provided the original work is properly cited, appropriate credit is given, any changes made indicated, and the use is non-commercial. See: http:// creativecommons.org/licenses/by-nc/4.0/.

(c) Author(s) (or their employer(s)) 2021. Re-use permitted under CC BY-NC. No commercial re-use. See rights and permissions. Published by BMJ.

Check for updates
To cite Martens G, Edouard P, Tscholl P, et al. Br J Sports Med 2021;55:187-188.

Accepted 31 October 2020

Published Online First 12 November 2020

Br J Sports Med 2021;55:187-188.

doi:10.1136/bjsports-2020-103087

\section{ORCID iDs}

Géraldine Martens http://orcid.org/0000-0001-70387165

Pascal Edouard http://orcid.org/0000-0003-1969-3612 Philippe Tscholl http://orcid.org/0000-0003-1702-7114 François Bieuzen http://orcid.org/0000-0002-96909168

Laurent Winkler http://orcid.org/0000-0002-5715-4807 Jan Cabri http://orcid.org/0000-0001-5539-4148

Axel Urhausen http://orcid.org/0000-0003-3564-5629 Gaël Guilhem http://orcid.org/0000-0002-0377-2060 Jean-Louis Croisier http://orcid.org/0000-0003-42040783

Patricia Thoreux http://orcid.org/0000-0002-3469-4210

Suzanne Leclerc http://orcid.org/0000-0001-9691-0532 Didier Hannouche http://orcid.org/0000-0003-20602394

Jean-François Kaux http://orcid.org/0000-0003-1939-

3652

Romain Seil http://orcid.org/0000-0001-8806-9384

\section{REFERENCES}

1 Ljungqvist $A$. Sports injury prevention: a key mandate for the IOC. Br J Sports Med 2008;42:391.

2 Engebretsen L, Bahr R, Cook JL, et al. The IOC centres of excellence bring prevention to sports medicine. $\mathrm{Br} J$ Sports Med 2014:48:1270-5.

3 Finch CF, Talpey S, Bradshaw A, et al. Research priorities of international sporting federations and the $I O C$ research centres. BMJ Open Sport Exerc Med 2016;2:e000168

4 IOC recognises 11 Research Centres worldwide for prevention of injury and protection of athlete health - Olympic News. Available: https://www.olympic.org/ news/ioc-recognises-11-research-centres-worldwidefor-prevention-of-injury-and-protection-of-athletehealth

5 Edouard P, Bieuzen F, Cabri J, et al. Strength lies in numbers! The Francophone ReFORM recognized by the IOC for advances in the prevention of sports injuries and the protection of athletes' health. J Traumatol du Sport 2019;894:65-6.

6 Roca A, Boum Y, Wachsmuth I. Plaidoyer contre I'exclusion des francophones dans La Recherche en santé mondiale. Lancet Glob Health 2019;7:e701-2.

7 van Mechelen W, Hlobil H, Kemper HC. Incidence, severity, aetiology and prevention of sports injuries. A review of concepts. Sports Med 1992;14:82-99. 